\title{
THE INFLUENCE OF AUTONOMIC VASOREGULATORY REFLEXES ON THE RATE OF SODIUM AND WATER EXCRETION IN MAN
}

\author{
By HENRY N. WAGNER, JR. \\ (From the National Heart Institute, National Institutes of Health, Bethesda, Md.)
}

(Submitted for publication March 27, 1957 ; accepted May 28, 1957)

In man, the function of the autonomic nervous system has been studied in two principal ways: 1 ) by determining the physiologic effects of paravertebral sympathectomy; and 2) by simulating or inhibiting the action of the autonomic nerves pharmacologically. In this study, a third approach has been used in an attempt to determine the role of the autonomic nervous system in physiologic processes. Studies were made of patients with marked autonomic hypofunction, manifested chiefly by orthostatic hypotension, diminished sweating and impotence. The patients studied had no other associated condition, such as generalized debility, Addison's disease, diabetes mellitus, syphilis, amyloidosis or somatic neurological disease, to which the autonomic dysfunction could be attributed. The disease process was very stable, changes occurring only over a period of several months or even years. In these patients it was found that the defect involved the parasympathetic as well as the sympathetic nervous systems (1). The cardiovascular, gastrointestinal, genitourinary and thermoregulatory systems were affected.

The purpose of this report is to present the results of studies of the hemodynamic and renal effects of acute changes in blood and extracellular fluid volume in these patients.

\section{DESCRIPTION OF PATIENTS}

Studies were performed in five patients and seven normal persons. A brief clinical description of three of the patients has been given in a previous report (1). Two additional patients have been studied. Patient L. S. (NIH 01-27-85) was a 21-year-old college student. Twenty-seven months prior to admission, he developed generalized weakness, anorexia and diarrhea. On standing, he complained of dizziness and blurring of vision. $\mathrm{He}$ also noted a marked watery nasal and post-nasal discharge associated with nasal stuffiness. There was occasional excessive lacrimation and salivation with pain in the region of the pa- rotid and submaxillary salivary glands, aggravated by eating. For several months he was bedridden with postural hypotension so severe that he had difficulty sitting up in bed. Upon the arrival of summer, five months after the onset of his illness, he noted that he no longer sweated, in marked contrast to the increased sweat gland activity that he noted at the beginning of his illness. Impotence and impaired ejaculations were also noted at about the same time. In the first month of illness, he had difficulty in micturition and defecation. Early in his illness, he was found to have an elevated spinal fluid protein (99 mg. per cent) which gradually fell to normal in two months. There were no other spinal fluid abnormalities. Of possible significance is the fact that a slightly papular, erythematous, pruritic rash appeared over his trunk during the first month of his illness.

After the first year of illness, the diarrhea, anorexia and postural symptoms improved somewhat. At the time of admission to the National Institutes of Health, 27 months after the onset of symptoms, he complained of chronic diarrhea and extreme generalized weakness, in addition to blurring of vision and syncope on standing. Positive physical findings were emaciation, slight pectus excavatum, and orthostatic hypotension. General and neurological examination were otherwise normal. Urinalysis and hemogram were within normal limits. Spinal fluid examinations were normal. Urinary 17 -ketosteroid and plasma hydrocortisone levels were normal.

Patient M. H. (NIH No. 01-36-95) was a 58year-old retired mail carrier. At age 46 he noticed sudden loss of sweating over the entire body with the exception of the axillae. At the same time he noted heat intolerance. Both have persisted essentially unchanged for the past 12 years. Eleven years ago he developed generalized weakness, aggravated by both erect posture and warm environmental temperatures. $\mathrm{He}$ had syncopal attacks associated with hyperventilation and clonic 


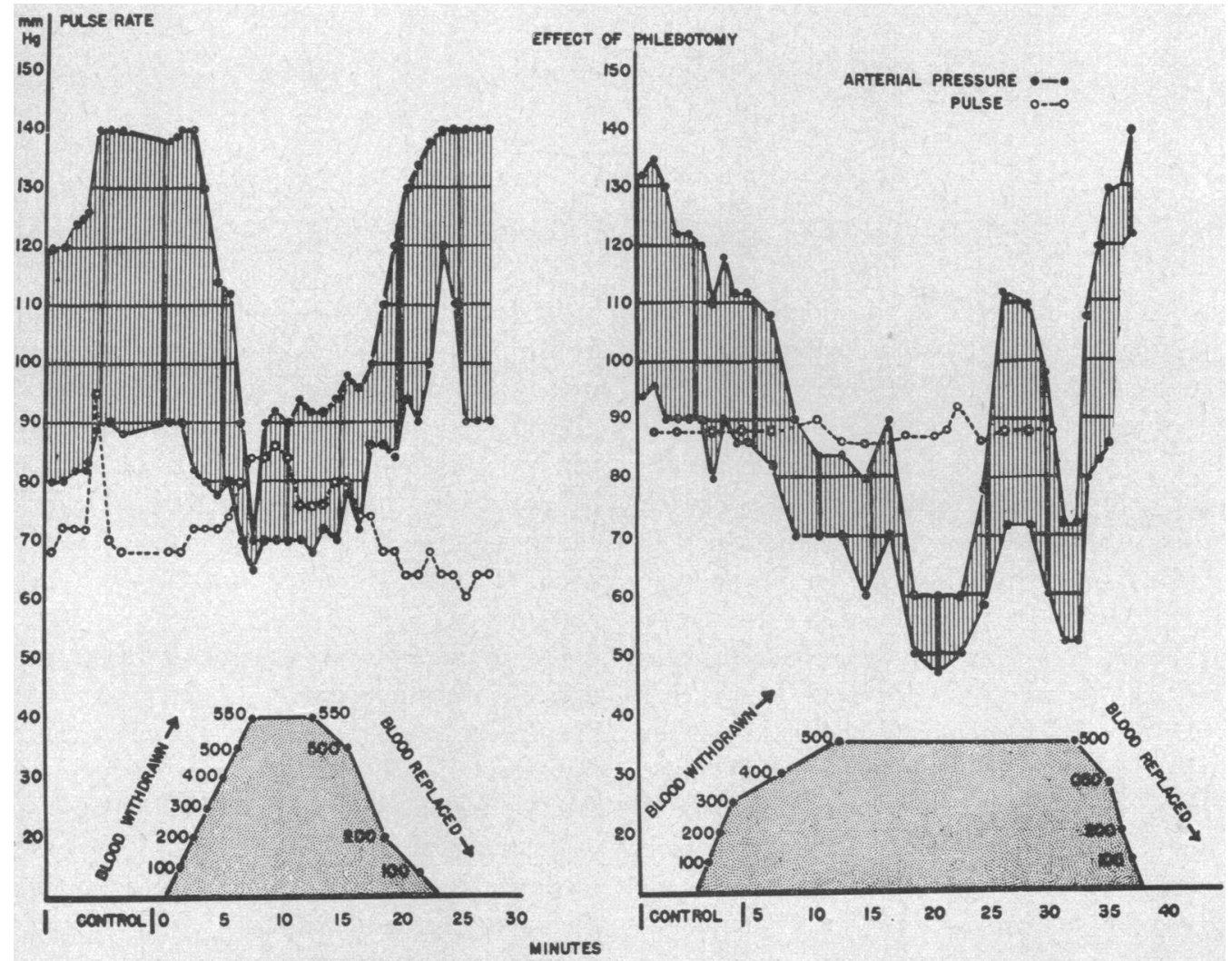

Fig. 1. The Effect of Rapid Removal and Replacement of Whole Blood on the Arterial Pressure of Two Patients With Postural Hypotension During Recumbency

movements of the extremities without incontinence. For two to three years prior to admission, the weakness had become more pronounced. Nine years prior to admission he noted impaired ejaculation progressing to complete impotence during the subsequent four years. Two years before admission he developed marked constipation to the extent that he has periods as long as five to seven days without bowel movements. The patient has not had diarrhea at any time during his illness. For the past two years, he has had urinary urgency and hesitancy. In July, 1947, the diagnosis of postural hypotension was made. At that time, his arterial pressure in the recumbent position was $130 / 82$, falling to $84 / 62$ on standing.

Positive physical findings were an arterial pressure of $180 / 110$, falling to $72 / 54$ on passive standing. He appeared older than 58 years. The skin was extremely dry and flaky. Nasal septum was perforated. No other abnormalities of the general or neurological physical examination were present, except as related to autonomic nervous system function. Urinalysis and hemogram were within normal limits. Plasma hydrocortisone level and response to ACTH were normal.

In all patients, graded passive tilting resulted in progressively lowered arterial pressure. In patient L.S. a rise in pulse rate occurred simultaneously. In patient M.H. no increase in pulse rate occurred with the fall in arterial pressure.

Involvement of the sympathetic nervous system of these patients was indicated by the diminished sweating, postural hypotension and absence of hypertensive "overshoot" following Valsalva maneuver. Abnormalities of the parasympathetic nervous system were suggested by: 1) the failure of atropine to alter the pulse rate; 2 ) the absence of bradycardia during the administration of norepinephrine; 3 ) the lack of effect on the pulse rate and arterial pressure of carotid sinus massage ; 
4) the inability to have erections; and 5) the failure of hypoglycemia to produce an increase in gastric acidity. ${ }^{1}$

\section{METHODS AND MATERIALS}

Brachial arterial pressures were measured by means of a sphygmomanometer. Mean arterial pressure was calculated as one-third of the pulse pressure plus diastolic pressure. In the studies in which whole blood was infused, mean pressure was recorded by means of a mercury manometer attached to an indwelling needle in the femoral artery. Glomerular filtration rate was measured by means of the clearance of inulin (2). Urine was collected by means of an indwelling rubber urethral catheter. At the beginning and end of each collection period, the bladder was emptied with $40 \mathrm{ml}$. of air, unless the urine flow was greater than $10 \mathrm{ml}$. per minute. The duration of the urine collection periods varied from 10 to 60 minutes. Osmolal concentration of urine and plasma was determined by the method of freezing-point depression. Sodium and potassium were measured by internal standard flame photometry. The sodium-retaining steroid used was 2-methyl, 9-alpha fluorohydrocortisone (Upjohn) (3). Purified arginine vasopressin and Pitressin (Parke-Davis) were also studied.

All studies were performed with the patients recumbent throughout. They were begun at approximately 9:00 A.M. Both patients and normal subjects were on an ad libitum diet prior to the studies. All subjects and patients were deprived of food and water for from 13 to 16 hours prior to the studies of renal function. The ages of the control subjects ranged from 18 to 72 years; the patients, from 21 to 66 .

\section{RESULTS}

\section{Effect on arterial pressure of changes in plasma and extracellular fluid (ECF) volume}

In previous studies of orthostatic hypotension, the inability of the patients to adjust their arterial pressure to postural changes has been emphasized. However, it can be demonstrated that the fall in arterial pressure that occurs in these patients when they assume an upright posture is merely a specific manifestation of a general inability to keep arterial pressure constant in the presence of variations in blood volume.

Figure 1 illustrates the effect of rapidly removing 500 milliliters of blood from each of two patients. The patients were recumbent in these studies and in those to be described subsequently. As the blood was withdrawn, a marked fall in ar-

1 Not all parasympathetic defects listed were present in all five patients. All sympathetic defects were present.
TABLE I

Pressor response to acute hypervolemia

\begin{tabular}{lcc}
\hline \hline & $\begin{array}{c}\text { Control } \\
\text { mean } \\
\text { pressure* }\end{array}$ & $\begin{array}{c}\text { Post-infusion } \\
\text { mean } \\
\text { pressuret }\end{array}$ \\
\hline $\begin{array}{c}\text { Whole blood } \ddagger \\
(500 \text { ml.) }\end{array}$ & 67 & 116 \\
$\begin{array}{c}\text { Normal saline } \\
(3,000 \text { ml.) } \\
\text { Albumin } \ddagger(50 \mathrm{Gm} .)\end{array}$ & 85 & 108 \\
$(200 \mathrm{ml})$. & 64 & 101
\end{tabular}

* Average of pressures recorded every three minutes for one hour prior to the beginning of the infusion.

$\uparrow$ Mean of the pressures obtained every three minuest for one hour.

$\ddagger$ Infused over a period of about 20 minutes.

Infused over a period of 60 minutes.

terial pressure occurred. When the blood was reinfused, the pressure returned to normal levels.

In addition, in these patients arterial pressure increased markedly when blood volume or ECF volume was suddenly expanded. In Table $I$ is shown the effect of the rapid infusion of whole blood, ${ }^{2}$ normal saline and albumin on the arterial pressure of one patient during recumbency. A marked increase in arterial pressure occurred in each case. In all patients, except one, similar results were obtained. The exception was the patient $M . H$., who was hypertensive in the recumbent position whenever studied. In this patient, the infusion of blood, saline or albumin did not significantly increase arterial pressure. In all patients, if the arterial pressure was elevated to hypertensive levels by means of vasopressin or adrenal steroid administration prior to expansion of plasma or ECF volume, no further increase in arterial pressure occurred. For example, in Table II are shown the results of acute expansion of the ECF volume with saline during the course of chronic 2-methyl, 9-alpha fluorohydrocortisone administration. As a result of the methyl fluorohydrocortisone, the arterial pressure was elevated during the control periods. When saline was rapidly infused, no further significant increase in arterial pressure occurred. Similar results were obtained when the control arterial pressure was elevated with vasopressin prior to the saline infusion.

In the normal subjects, the infusion of $3,000 \mathrm{ml}$.

2 The whole blood administered was removed from the patient in small amounts in the week prior to its readministration. 
TABLE II

Pressure response to acute hypervolemia during methyl fluorohydrocortisone administration *

\begin{tabular}{clcc}
\hline \hline & Patient & $\begin{array}{c}\text { Control } \\
\text { mean } \\
\text { pressure }\end{array}$ & $\begin{array}{c}\text { Post-infusion } \\
\text { mean } \\
\text { pressure }\end{array}$ \\
\hline $\begin{array}{clcc}\text { Normal saline } \\
(3,000 \mathrm{ml} .)\end{array}$ & B. B. & 113 & 120 \\
& L.S. & 118 & 122 \\
& M. H. & 121 & 126 \\
Albumin & L. S. & 116 & 118 \\
$(50 \mathrm{Gm})$. & B. B. & 113 & 118 \\
\hline
\end{tabular}

* Pressures were recorded as described in Table I.

of saline did not significantly increase arterial pressure. The effect of whole blood was not studied in normal subjects.

\section{Renal effects of the rapid administration of isotonic saline}

In addition to the abnormal hemodynamic response of these patients to expansion of extracellular fluid volume, there was a striking difference between these patients and normal persons in their ability to excrete both sodium and water in response to the administration of isotonic sodium chloride solutions ( $154 \mathrm{mEq}$. per L.). In seven normal persons and in four patients, food and water were withheld for 13 to 16 hours. Isotonic sodium chloride solution was then administered at a rate of $50 \mathrm{ml}$. per minute for one hour. Table III summarizes the results of these studies. During the infusion of isotonic saline to the patients in the recumbent position, average urine flow was 23 $\mathrm{ml}$. per minute, ranging from 18 to $31 \mathrm{ml}$. per minute; sodium excretion during the hour's infusion was $80.3 \mathrm{mEq}$. per hour, ranging from 45 to 128
$\mathrm{mEq}$. per hour; and the average maximum rate of sodium excretion during the infusion was $2,500 \mathrm{mi}$ croequivalents per minute, ranging from 1,600 to 4,000 . In contrast, in the normal persons studied under similar conditions, corresponding values were $6.3 \mathrm{ml}$. per minute (range, 1.4 to 12.7 ) ; 14.9 $\mathrm{mEq}$. per hour (0.8 to 19.9); and 702 microequivalents per minute (220 to 1,450$)$. The ranges of these measurements did not overlap in the two groups of persons. Figure 2 (A, B) shows the results of these experiments graphically. In part $A$, it may be seen that in the normal persons, a moderate increase in sodium excretion occurred in association with the infusion. In contrast, in part B it may be seen that in the four patients studied a marked and rapid increase in sodium excretion occurred, beginning during the period of the infusion.

Figure 3 (A, B) shows the effect of the infusion of isotonic saline on the excretion of solute-free water in the two groups. Solute-free water $\left(\mathrm{C}_{\mathrm{H}_{2} \mathrm{O}}\right)$ is defined as the amount of water excreted per minute in excess of that required to produce an isosmotic urine. It is calculated by subtracting osmolal clearance ( $C_{0 s m}$ ) from urine flow (V). It is positive in the case of urines that are hypotonic to plasma and negative in the case of hypertonic urines.

In addition to the enhanced sodium excretion, in the patients there was a great increase in the excretion of solute-free water as isotonic saline was infused. In all patients the urine became hypotonic. In contrast, in Figure 3, part A, it may be seen that in normal persons the urine became hypotonic in only four persons and in none of the control persons was the increase in solute-free water as great as that observed in the patients.

TABLE II

Rewal response to isotonic saline administration $(3,000 \mathrm{ml}$.) in normal persons and patients with idiopathic postural hypotension

\begin{tabular}{|c|c|c|c|c|}
\hline & \multicolumn{2}{|c|}{ Patients (four) } & \multicolumn{2}{|c|}{ Control subjects (seven) } \\
\hline & Mean & Range & Mean & Range \\
\hline $\begin{array}{l}\text { Urine flow } \\
(\mathrm{ml} . / \mathrm{min} .)\end{array}$ & 23 & $18-31$ & 6 & $1-13$ \\
\hline $\begin{array}{l}\text { Sodium excretion during the hour's infusion } \\
\text { (milliequivalents/hour) }\end{array}$ & 80 & $45-128$ & 15 & $1-20$ \\
\hline $\begin{array}{l}\text { Average maximal sodium excretion } \\
\text { (microequivalents/minute) }\end{array}$ & 2,500 & $1,600-4,000$ & 702 & $220-1,450$ \\
\hline
\end{tabular}




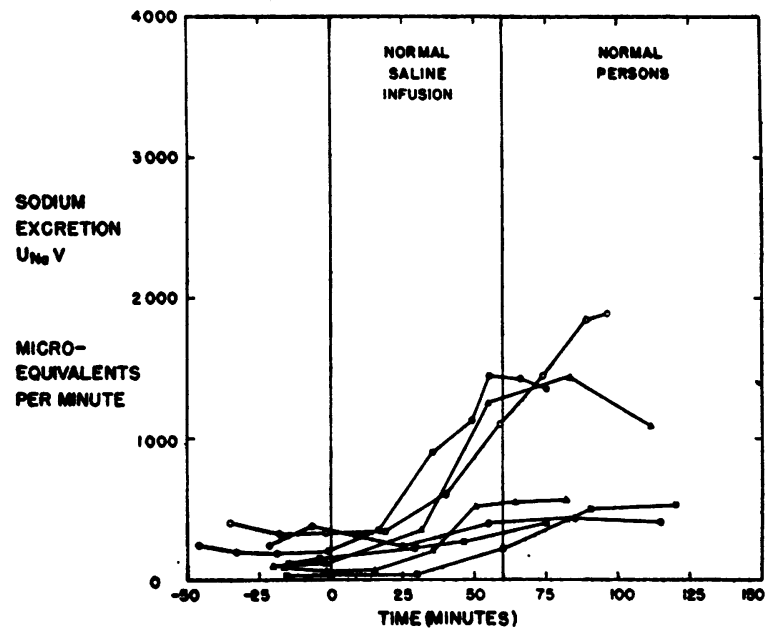

(A)

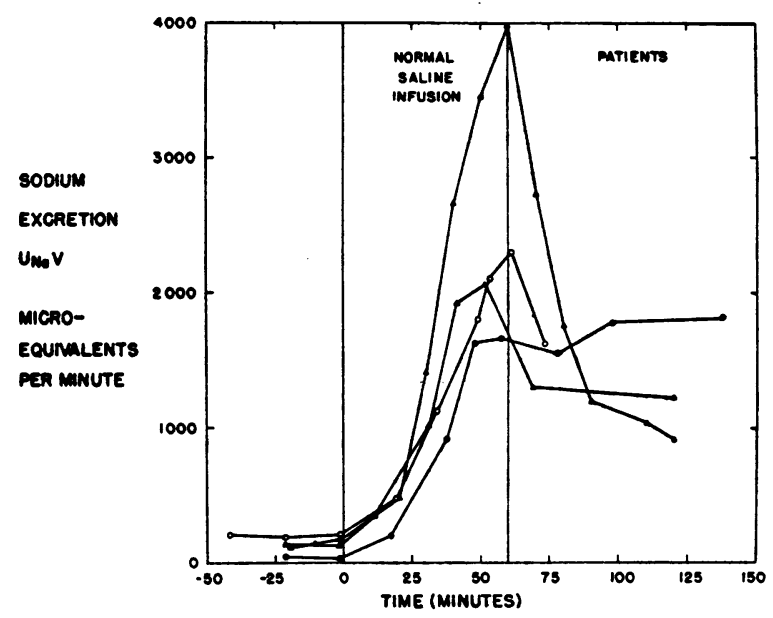

(B)

Fig. 2. The Effect on Sodium Excretion of the INFUSION OF Three Liters of IsOTONIC SODIUM ChLORIDE Following 13 to 16 Hours Food and Water DeprivaTION

The persons were recumbent throughout the study. A refers to 7 normal subjects; B refers to identical studies in 4 persons with postural hypotension.

\section{Effect of vasopressin on the excretion of solute-free water}

The transition of the urine from hypertonic to hypotonic in association with the marked increase in sodium excretion was thought to be due to insufficient antidiuretic hormone $(\mathrm{ADH})$ in the presence of an acutely rising sodium excretion (4). Accordingly, experiments were performed in which exogenous vasopressin was administered to supplement the endogenous $\mathrm{ADH}$ resulting from the

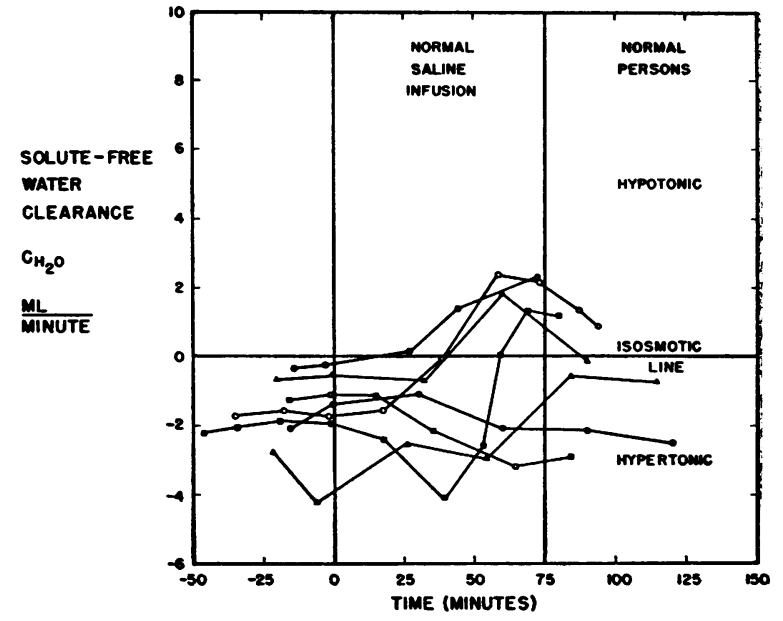

(A)

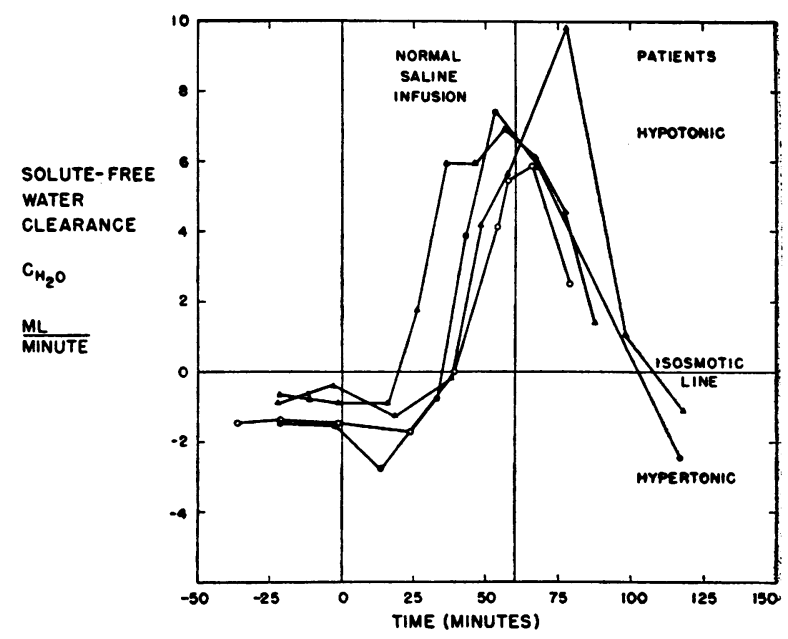

(B)

Fig. 3. The Effect on Solute-Free Water ExcreTION OF THE INFUSION OF THREE Liters of Isotonic SOdium Chloride Solutions Following 13 and 16 Hours Water Deprivation

In figure $\mathrm{A}$, the infusion ended at 60 minutes, not 75 minutes. A, normal persons; B, patients with orthostatic hypotension.

13 to 16 hour water deprivation. An example of such a study is seen in Figure 4. In this patient, food and water were withheld for 13 hours. Dehydration and the associated endogenous ADH release resulted in the formation of hypertonic urines. As solute excretion then increased acutely during the infusion of isotonic saline, the urine became hypotonic and solute-free water clearance became positive. On another day (lower line on Figure 4 ), the experiment was repeated, but 5 milliunits 


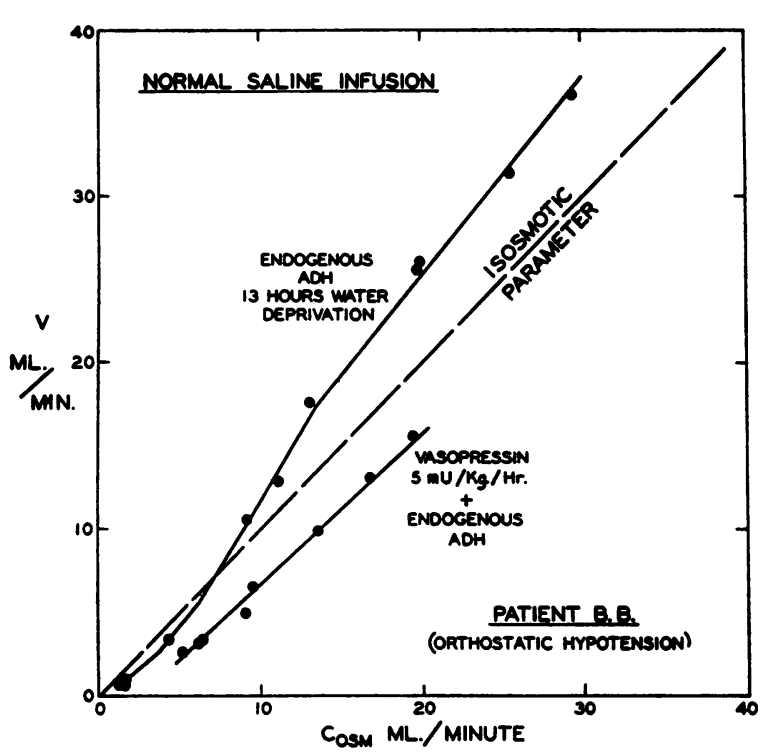

Fig. 4. The Relationship Between Urine Flow ANd Solute Excretion During the Infusion of Normal Saline Solutions in a Patient With Postural HYPOTENSION

The upper line was obtained after 13 to 16 hours water deprivation. The lower line illustrates the relationship during the administration of additional exogenous vasopressin under similar conditions.

per kilo per hour of vasopressin were administered throughout. Despite the rapid increase in sodium excretion, the urine remained hypertonic to plasma.

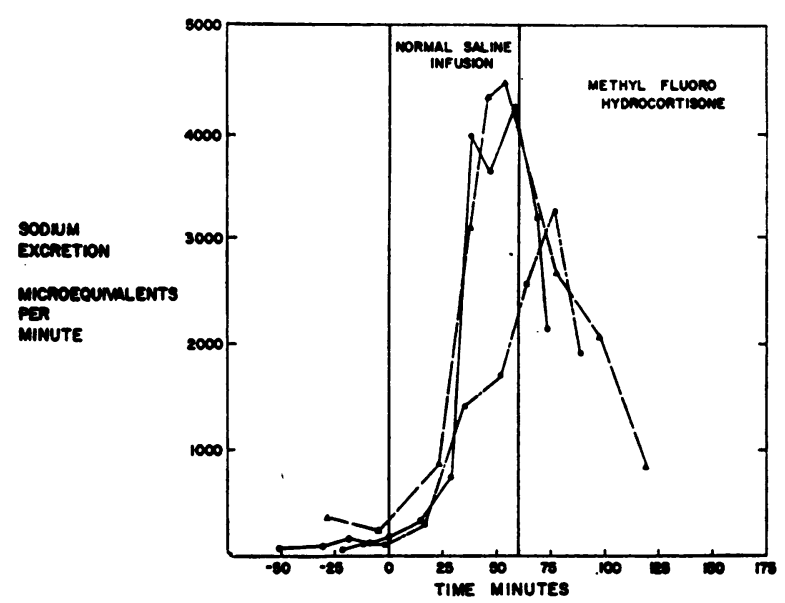

Fig. 5. The Effect on Sodium Excretion of the Infusion of 3,000 ML. of Isotonic Sodium Chloride Solutions During the Chronic Administration of 2-Methyl, 9-Alpha Fluorohydrocortisone to Patient With Orthostatic Hypotension
IV. Effect of adrenal sodium-retaining steroids on the enhanced sodium excretion

The enhanced sodium excretion that occurred when isotonic saline was infused could not be prevented by the chronic administration of $0.5 \mathrm{mg}$. per day of 2-methyl, 9-alpha fluorohydrocortisone by mouth, or by the acute administration of $1 \mathrm{mi}$ crogram per minute intravenously. In Figure 5 are shown the results of the infusion of isotonic saline during the chronic ${ }^{3}$ administration of 2 methyl, 9-alpha fluorohydrocortisone. It can be seen that the sodium excretion in these studies averaged $120 \mathrm{mEq}$. per hour during the infusion, as compared to $80 \mathrm{mEq}$. per hour in the same patients when the experiments were performed without methyl fluorohydrocortisone. The failure of methyl fluorohydrocortisone to prevent the sodium excretion was interpreted as making it unlikely that the enhanced sodium excretion in the patients during ECF expansion was due to decreased aldosterone activity.

\section{$V$. Effect of rapid saline infusion on glomerular} filtration rate (GFR)

In the patients, the increase in glomerular filtration rate during the saline infusion ranged from 19 to 63 per cent. In the control subjects, the increase in GFR ranged from -15 to 12 per cent.

TABLE IV

Glomerular filtration rate in patients with orthostatic hypotension and in control subjects before and after the rapid infusion of $3,000 \mathrm{ml}$. of isotonic sodium chloride*

\begin{tabular}{lrrrrr}
\hline \hline & $\begin{array}{c}\text { Mean of } \\
\text { control } \\
\text { periods }\end{array}$ & Range & $\begin{array}{c}\text { Mean of } \\
\text { periods } \\
\text { during } \\
\text { infusion }\end{array}$ & Range & $\begin{array}{r}\text { Change } \\
\%\end{array}$ \\
\hline Patient & & & & & \\
B. B. & 56 & $56-57$ & 91 & $79-98$ & 63 \\
M. H. & 84 & $83-85$ & 100 & $90-109$ & 19 \\
H. C. & 89 & $87-91$ & 106 & $96-110$ & 19 \\
L. S. & 140 & $134-143$ & 176 & $145-196$ & 26 \\
Subject & & & & & \\
V.S. & 94 & $92-97$ & 80 & $76-83$ & -15 \\
G.S. & 124 & $120-128$ & 135 & $125-140$ & 8 \\
R.S. & 131 & $129-132$ & 147 & $132-168$ & 12 \\
L. B. & 109 & $103-121$ & 120 & $103-134$ & 10 \\
I.S. & 147 & $140-155$ & 160 & $151-170$ & 9 \\
& & & & & \\
\hline
\end{tabular}

* Inulin clearance determinations were performed in only five of the seven control subjects.

8 At least three weeks of continuous administration prior to the acute study. 
TABLE V

Effect of sodium chloride infusions on urine flow and glomerular fillration rate in normal persons and in patients with orthostatic hypotension

\begin{tabular}{|c|c|c|c|c|c|c|c|c|c|c|c|c|c|}
\hline $\begin{array}{l}\text { Period.. } \\
\text { Subject }\end{array}$ & & -3 & -2 & -1 & 1 & 2 & 3 & 4 & 5 & 6 & 7 & 8 & 9 \\
\hline B. B.* & $\begin{array}{l}\mathrm{V} \dagger \\
\mathrm{L} \dagger \\
\mathrm{C}_{\text {in }} \dagger\end{array}$ & $\begin{array}{r}0.7 \\
10 \\
56\end{array}$ & $\begin{array}{r}0.9 \\
10 \\
57\end{array}$ & $\begin{array}{r}0.7 \\
10 \\
56\end{array}$ & $\begin{array}{r}3.4 \\
20 \\
79\end{array}$ & $\begin{array}{r}25.6 \\
10 \\
96\end{array}$ & $\begin{array}{r}31.4 \\
10 \\
90\end{array}$ & $\begin{array}{r}36.2 \\
10 \\
98\end{array}$ & $\begin{array}{r}26.0 \\
10 \\
92\end{array}$ & $\begin{array}{r}17.5 \\
10 \\
74\end{array}$ & $\begin{array}{r}10.5 \\
10 \\
65\end{array}$ & $\begin{array}{r}6.0 \\
30 \\
72\end{array}$ & $\begin{array}{r}5.2 \\
10 \\
71\end{array}$ \\
\hline M. H.* & $\begin{array}{l}\mathrm{V} \\
\mathrm{L} \\
\mathrm{C}_{\text {in }}\end{array}$ & $\begin{array}{r}0.7 \\
10 \\
83\end{array}$ & $\begin{array}{r}0.95 \\
10 \\
85\end{array}$ & $\begin{array}{r}0.7 \\
9\end{array}$ & $\begin{array}{r}2.0 \\
21 \\
101\end{array}$ & $\begin{array}{r}8.7 \\
20 \\
109\end{array}$ & $\begin{array}{r}17.4 \\
10 \\
104\end{array}$ & $\begin{array}{r}18.4 \\
10 \\
90\end{array}$ & $\begin{array}{r}16.6 \\
20 \\
97\end{array}$ & $\begin{array}{r}15.8 \\
20 \\
102\end{array}$ & $\begin{array}{r}13.9 \\
20 \\
120\end{array}$ & & \\
\hline H. C. ${ }^{*}$ & $\begin{array}{l}\mathrm{V} \\
\mathrm{L} \\
\mathbf{C}_{\text {in }}\end{array}$ & & $\begin{array}{l}1.0 \\
20 \\
91\end{array}$ & $\begin{array}{r}0.9 \\
20 \\
87\end{array}$ & $\begin{array}{l}2.3 \\
13\end{array}$ & $\begin{array}{r}9.7 \\
20 \\
106\end{array}$ & $\begin{array}{r}21.3 \\
10 \\
110\end{array}$ & $\begin{array}{r}23.7 \\
10 \\
110\end{array}$ & $\begin{array}{r}16.0 \\
15 \\
96\end{array}$ & $\begin{array}{r}8.2 \\
49 \\
107\end{array}$ & & & \\
\hline L. S.* & $\begin{array}{l}\mathrm{V} \\
\mathrm{L} \\
\mathrm{C}_{\text {in }}\end{array}$ & $\begin{array}{r}2.2 \\
19 \\
142\end{array}$ & $\begin{array}{r}2.0 \\
19 \\
134\end{array}$ & $\begin{array}{r}2.1 \\
20 \\
143\end{array}$ & $\begin{array}{r}3.4 \\
20 \\
170\end{array}$ & $\begin{array}{r}9.5 \\
16\end{array}$ & $\begin{array}{r}17.7 \\
15 \\
176\end{array}$ & $\begin{array}{r}21.2 \\
14 \\
196\end{array}$ & $\begin{array}{r}22.9 \\
8 \\
169\end{array}$ & $\begin{array}{r}15.0 \\
12 \\
145\end{array}$ & & & \\
\hline V.S. & $\begin{array}{l}\mathrm{V} \\
\mathrm{L} \\
\mathrm{C}_{\text {in }}\end{array}$ & & $\begin{array}{r}1.1 \\
15 \\
97\end{array}$ & $\begin{array}{r}0.9 \\
15 \\
92\end{array}$ & $\begin{array}{r}1.4 \\
34 \\
80\end{array}$ & $\begin{array}{r}2.6 \\
20 \\
82\end{array}$ & $\begin{array}{r}2.9 \\
20 \\
82\end{array}$ & $\begin{array}{r}2.0 \\
17 \\
76\end{array}$ & & & & & \\
\hline G. S. & $\begin{array}{l}\mathrm{V} \\
\mathrm{L} \\
\mathrm{C}_{\mathrm{in}}\end{array}$ & & $\begin{array}{r}1.2 \\
15 \\
120\end{array}$ & $\begin{array}{r}2.0 \\
15 \\
128\end{array}$ & $\begin{array}{r}1.4 \\
32 \\
125\end{array}$ & $\begin{array}{r}4.1 \\
28 \\
135\end{array}$ & $\begin{array}{r}5.4 \\
30 \\
140\end{array}$ & $\begin{array}{r}4.7 \\
30 \\
140\end{array}$ & & & & & \\
\hline R. S. & $\begin{array}{l}\mathrm{V} \\
\mathrm{L} \\
\mathbf{C}_{\text {in }}\end{array}$ & & $\begin{array}{r}0.8 \\
16 \\
129\end{array}$ & $\begin{array}{r}0.4 \\
15 \\
132\end{array}$ & $\begin{array}{r}0.4 \\
15 \\
133\end{array}$ & $\begin{array}{r}1.0 \\
20 \\
168\end{array}$ & $\begin{array}{r}2.9 \\
15 \\
167\end{array}$ & $\begin{array}{r}3.4 \\
14 \\
132\end{array}$ & $\begin{array}{r}4.0 \\
19 \\
134\end{array}$ & & & & \\
\hline L. B. & $\begin{array}{l}\mathrm{V} \\
\mathrm{L} \\
\mathbf{C}_{\mathrm{in}}\end{array}$ & $\begin{array}{r}2.7 \\
17 \\
121\end{array}$ & $\begin{array}{r}2.1 \\
17 \\
103\end{array}$ & $\begin{array}{r}2.2 \\
16 \\
103\end{array}$ & $\begin{array}{r}2.3 \\
20 \\
103\end{array}$ & $\begin{array}{r}4.6 \\
21 \\
115\end{array}$ & $\begin{array}{r}11.1 \\
19 \\
134\end{array}$ & $\begin{array}{r}13.3 \\
15 \\
125\end{array}$ & $\begin{array}{r}15.2 \\
15 \\
125\end{array}$ & $\begin{array}{r}15.2 \\
8 \\
125\end{array}$ & & & \\
\hline I. S. & $\begin{array}{l}\mathrm{V} \\
\mathbf{L} \\
\mathbf{C}_{\text {in }}\end{array}$ & $\begin{array}{r}1.7 \\
27 \\
155\end{array}$ & $\begin{array}{r}1.9 \\
13 \\
140\end{array}$ & $\begin{array}{r}1.7 \\
33 \\
145\end{array}$ & $\begin{array}{r}1.4 \\
19 \\
168\end{array}$ & $\begin{array}{r}4.3 \\
21 \\
151\end{array}$ & $\begin{array}{r}7.4 \\
14 \\
156\end{array}$ & $\begin{array}{r}12.7 \\
6 \\
170\end{array}$ & $\begin{array}{r}13.0 \\
11 \\
157\end{array}$ & $\begin{array}{r}12.0 \\
9 \\
173\end{array}$ & & & \\
\hline
\end{tabular}

* = Patient with orthostatic hypotension.

$\dagger \vec{V}=$ Urine flow (ml. per minute); $L=$ Length of period in minutes; $C_{i n}=$ Inulin clearance.

The results are summarized in Table IV. In both the patients and the control subjects, errors occurred in the estimation of glomerular filtration rate as a result of the changing urine flows and associated dead space and "wash out" errors. To enable an evaluation of the data Table V lists the urine flow, length of collection period and inulin clearance for the individual studies. During the collection periods when urine flow was not changing markedly from one period to the next, it was believed that the glomerular filtration rate was accurately determined. A detailed protocol from one of the studies of a patient with orthostatic hypotension is presented in Table VI.

In the patients, the enhanced excretion of sodium might be attributed to the greater and more rapid elevation of the GFR associated with ECF expansion. In the normal persons the moderate increase in sodium excretion could also be correlated with the change of GFR. It does not necessarily follow that the increase in sodium excretion is due to the increase in GFR. It is also possible that tubular function per se is subject to nervous influences.

\section{DISCUSSION}

A previous study indicated that patients with hypofunction of the autonomic nervous system have an increased sensitivity to vasoactive substances of diverse types, both pressor and depressor (1). For example, vasopressin and norepinephrine caused marked hypertension, and oxytocin and nitroglycerine marked hypotension. The wide spectrum of vasoactive substance to which these patients respond suggests that the increased sensitivity results from the absence of vasoregu- 
TABLE VI

Effect of isotonic sodium chloride infusion on renal function in orthostatic hypotension *

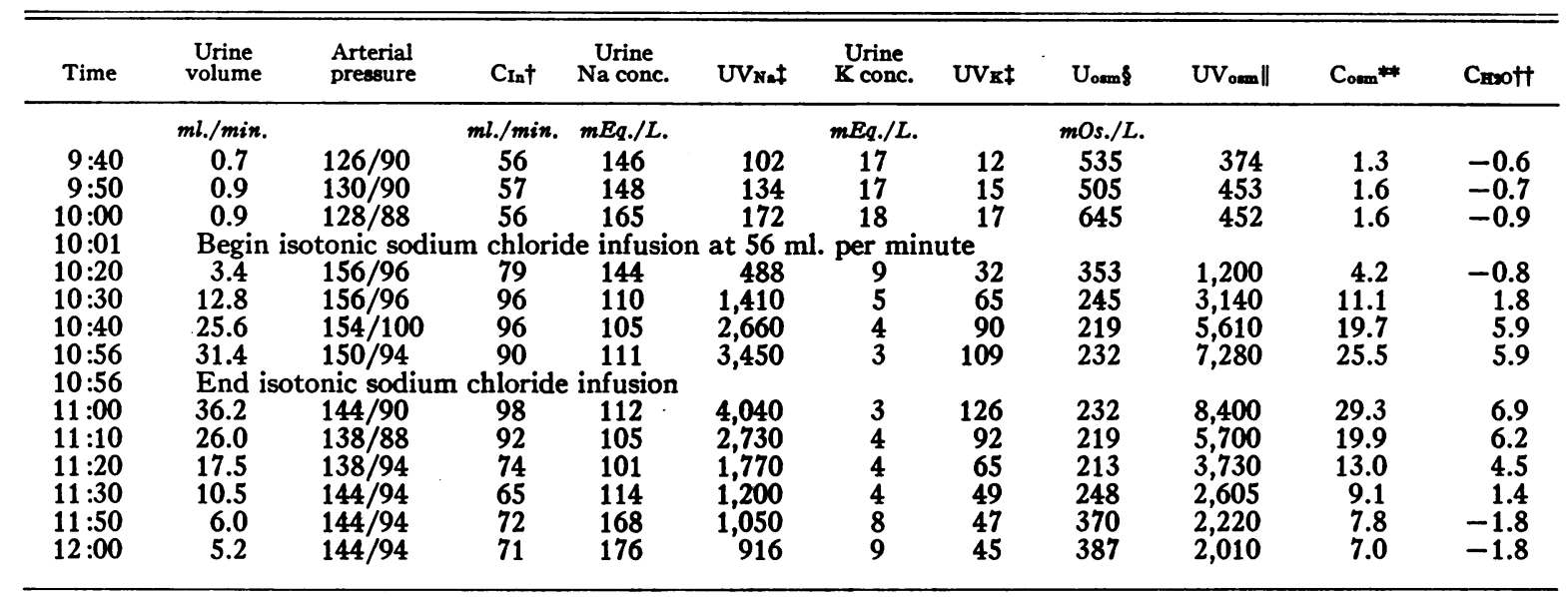

* Patient B. B. Time: 8:40, Inulin prime; then $20 \mathrm{mg}$. per minute inulin infusion in 5 per cent glucose at $1 \mathrm{ml}$ per minute.

$f$ Inulin clearance.

$\$$ Sodium and potassium excretion in microequivalents per minute.

8 Urine osmolality.

Total solute excretion in microosmoles per minute.

* Clearance of total solute.

it Solute-free water clearance.

latory reflexes. In normal man, these reflexes compensate for changes in arterial pressure from any cause and maintain arterial pressure within narrow homeostatic limits.

Thus, in normal man, expansion of extracellular fluid volume with saline did not result in significant alteration of arterial pressure. In contrast, volume changes in the patients with deficient autonomic reflexes resulted in profound changes in arterial pressure, showing that the patients lack the ability to maintain circulatory homeostasis.

In association with the lability of the arterial pressure, these patients have a labile glomerular filtration rate. Passive tilting from a recumbent to an upright posture resulted in a marked fall in glomerular filtration rate and decreased sodium excretion. On the other hand, rapid expansion of the extracellular fluid volume resulted in an enhanced sodium excretion in these patients when compared to normal persons. In the patients the increased rate of excretion could be attributed to a rapid increase in glomerular filtration rate.

The actual level of the arterial pressure could not be correlated with the change in GFR and sodium excretion. This was demonstrated in the studies in which saline was infused during the hy- pertensive state associated with methyl fluorohydrocortisone administration: Despite the lack of any further increase in arterial pressure, the GFR and sodium excretion increased markedly.

The hemodynamic and renal responses of these patients to saline administration are analogous to those observed in dogs. The dog has less welldeveloped autonomic vasoregulatory reflexes than man, consistent with a quadrapedal as compared to a bipedal habitus (5). The dog, as well as other quadrapeds studied, has a labile glomerular filtration rate and consequently is able to excrete rapidly large quantities of exogenously administered salt $(6,7)$. In normal man, the response of the GFR to intravenously administered salt is less than that observed in the dog. For example, Crawford and Ludemann (8) found that isotonic saline administered at rates as high as $56 \mathrm{ml}$. per minute increased the GFR by more than 10 per cent in only 4 of 29 subjects studied. In the present study, in none of the control subjects was the magnitude of increase in GFR as great as that observed in the patients. Furthermore, within the control group, the variations in sodium excretion in response to saline administration could be correlated with the change in GFR.

To what is the relative stability of the glomeru- 
lar filtration rate in man attributable? It seems possible that the presence of autonomic vasoregulatory reflexes functioning to maintain circulatory homeostasis may result in normal man's relative inability to increase his glomerular filtration rate rapidly and thereby excrete excesses of salt. This hypothesis is supported by the finding that persons with absent vasoregulatory reflexes have a labile filtration rate and an enhanced ability to excrete salt rapidly. Further studies are in progress to test this hypothesis in normal man during ganglionic blockade.

\section{SUMMARY}

1. Patients with idiopathic hypofunction of the autonomic nervous system, manifested by postural hypotension, hypohidrosis and impotence, have been found to have an enhanced ability to excrete sodium and solute-free water in response to the rapid infusion of isotonic saline.

2. The augmented solute-free water excretion could be prevented by the administration of vasopressin.

3. The sodium excretion was not prevented by the administration of sodium-retaining adrenal steroids.

4. The enhanced sodium excretion was associated with acute elevation of glomerular filtration rate associated with ECF expansion.

5. In addition, acute expansion or depletion of blood or extracellular fluid volume in these patients resulted in profound changes in arterial pressure, indicating a lack of ability to maintain circulatory homeostasis.

6. The experiments suggest that the presence of well-developed autonomic vasoregulatory reflexes functioning to maintain circulatory homeo- stasis may result in man's relative inability to rapidly increase his glomerular filtration rate and thereby rapidly excrete excesses of salt.

\section{ACKNOWLEDGMENTS}

I would like to acknowledge my indebtedness to Drs. Kendall A. Elsom and Roscoe F. Morton, who referred two of the patients with orthostatic hypotension, and to Drs. Harold Dodge and Eugene Braunwald, who collaborated in several of the studies.

\section{REFERENCES}

1. Wagner, H. N., Jr., and Braunwald, E., The pressor effect of the antidiuretic principle of the posterior pituitary in orthostatic hypotension. J. Clin. Invest., 1956, 35, 1412.

2. Walser, M., Davidson, D. G., and Orloff, J., The renal clearance of alkali-stable inulin. J. Clin. Invest., 1955, 34, 1520.

3. Liddle, G. W., and Richard, J. E., 2-methyl hydrocortisones: a new series of steroids with enhanced potency and prolonged action. Science, 1956, 123, 324.

4. Wagner, H. N., Jr., Davidson, D. G., and Orloff, J., The graded effect of purified vasopressin and urinary solute on the excretion of solute-free water. Clin. Research Proc., 1957, 5, 23.

5. Mayerson, H. S., Orthostatic circulatory failure ("gravity shock") in the dog. Am. J. Physiol., 1944, 141, 227.

6. Wesson, L. G., Jr., Anslow, W. P., Jr., Raisz, L. G., Bolomey, A. A., and Ladd, M., The effect of sustained expansion of extracellular fluid volume upon filtration rate, renal plasma flow and electrolyte and water excretion in the dog. Am. J. Physiol., 1950, 162, 677.

7. Dicker, S. E., The action of mersalyl, calomel, and theophylline sodium acetate on the kidney of the rat. Brit. J. Pharm., 1946, 1, 194.

8. Crawford, B., and Ludemann, $H$., The renal response to intravenous injection of sodium chloride solutions in man. J. Clin. Invest., 1951, 30, 1456. 